\title{
Notas para uma História da Sociedade Brasileira de Física*
}

\author{
Notes for a History of the Brazilian Physical Society \\ Silvio R. A. Salinas \\ Instituto de Física, Universidade de São Paulo, \\ Caixa Postal 66318, 05315-970 São Paulo, SP
}

Recebido em 27 de agosto de 2001. Aceito em 31 de agosto de 2001.

\begin{abstract}
Este artigo é uma versão do meu discurso por ocasião da inauguração do edifício próprio da Sociedade Brasileira de Física (SBF) em 1998. A partir da análise dos Boletins e Atas de reuniões, procuro discutir aspectos relevantes da atuação da SBF nos últimos trinta anos. Espero que este trabalho preliminar consiga encorajar historiadores a escrever uma história completa da SBF.

This paper was addressed at the inauguration of the new headquarters of the Brazilian Physical Society (SBF) in 1998. On the basis of the Bulletins and meeting reports, I try to discuss relevant aspects of the society in the last thirty years. I hope this preliminary work may encourage historians to write a more complete history of the SBF.
\end{abstract}

\section{Introdução}

Há cerca de três anos, por ocasião da inauguração da sede própria da Sociedade Brasileira de Física (SBF), em pequeno edifício construído no coração do Instituto de Física da USP, César Sá Barreto me pediu que falasse sobre alguns aspectos da atuação da nossa sociedade durante os últimos trinta anos. Fiz uma pesquisa, necessariamente rudimentar, nos Boletins e nas atas de reuniões da $\mathrm{SBF}$, e produzi umas notas que foram lidas na solenidade de inauguração. Surgiu agora a oportunidade de publicar um texto neste volume dedicado à Amelia. Não tive tempo, e nem competência, para aprofundar a pesquisa inicial. Mas vou acabar falando um pouco da própria Amelia, pois ela participou ativamente do período inicial de formação da SBF. Além disso, talvez a Amelia e os seus associados possam ser estimulados a retomar o assunto a fim de escrever uma história, de fato, da Sociedade Brasileira de Física.

\section{Fundação da Sociedade Bra- sileira de Física (SBF)}

A assembléia de fundação da SBF foi realizada no dia 14 de julho de 1966, em Blumenau, Santa Catarina, durante a XVIII Reunião Anual da Sociedade Brasileira para o Progresso da Ciência (SBPC). Foi presidida por José Goldemberg, do Departamento de Física da antiga
Faculdade de Filosofia, Ciências e Letras da USP, secretário da Comissão de Física da SBPC, e secretariada por Paulo Leal Ferreira, do Instituto de Física Teórica (IFT) de São Paulo.

Durante a assembléia de fundação foi discutida e votada uma proposta de estatuto da sociedade, elaborada por uma comissão de físicos designada durante a XVI Reunião Anual da SBPC, realizada em Ribeirão Preto, em 1964, incorporando sugestões que haviam sido apresentadas durante a reunião da SBPC em 1965, em Belo Horizonte. O estatuto aprovado em Blumenau, redigido principalmente por Jayme Tiomno, Amelia Imperio Hamburger, Ross Alan Douglas e Sergio Mascarenhas, incluindo algumas modificações aprovadas no ano seguinte, continua sendo o documento básico da sociedade.

Na assembléia de Blumenau, os Membros Fundadores também elegeram a diretoria provisória, sob a presidência de Oscar Sala, do Departamento de Física da antiga Faculdade de Filosofia, Ciências e Letras da USP, e escolheram a cidade de São Paulo para sede da SBF. Como primeira contribuição ao país, a diretoria da nova sociedade deveria realizar um "estudo sobre a situação e as necessidades da física no Brasil a fim de apresentar às autoridades competentes".

\footnotetext{
*Publicado em A Cultura da Física: Contribuiçôes em Homenagem a Amelia Imperio Hamburger, organizado por Antônio Augusto P. Videira e Silvio R. A. Salinas, Editora Livraria da Física, São Paulo (2001).
} 


\section{A SBF na ditadura - 1969}

Em abril de 69 foram aposentados pelo regime militar o presidente da SBF, José Leite Lopes, no seu segundo mandato, o vice-presidente, Jaime Tiomno, e o conselheiro Mario Schenberg. Jaime Tiomno nem chega a tomar posse - numa carta comovida à diretoria apresenta a sua renúncia e faz um apelo para que a sociedade continue funcionando. Leite Lopes também renuncia e viaja para os Estados Unidos. Vários outros físicos foram aposentados na mesma ocasião: Plínio Sussekind da Rocha, Elisa Frota Pessoa e Sarah de Castro Barbosa, no Rio de Janeiro. Mais tarde houve físicos aposentados em Minas Gerais e no Rio Grande do Sul.

$\mathrm{O}$ Boletim número 1 da SBF, editado pelo secretário-geral Ernst W. Hamburger, surge em novembro de 69 sob o signo do protesto. O CNPq havia recusado um pedido de recursos da Diretoria anterior para publicar uma revista científica. Nessas condições, a solução foi conseguir o patrocínio de anunciantes para publicar um boletim com "informações de interesse para os professores e pesquisadores de física brasileiros". A idéia consistia em suplementar os boletins do Centro LatinoAmericano de Física, CLAF, que desapareceriam logo depois, e preencher o papel das antigas "Informações entre Físicos", publicadas pelo IFT em São Paulo. O Boletim número 1 registra os protestos internacionais contra as aposentadorias: manifestações de pelo menos dez nobelistas, cartas da Société Française de Physique e da Latin American Studies Association de Washington, notícias em Nature, Physics Today e Scientific Research.

Em 69 a diretoria funciona em São Paulo: a presidência é exercida, de fato, pelo secretário-geral, Ernst W. Hamburger; a secretaria, por Carlos Alberto Dias (UFBA); a secretaria de ensino, por Ramayana Gazzinelli (UFMG); e a tesouraria, por Pedro Rocha de Andrade (UFRGS). Criam-se as primeiras "divisões estaduais" da SBF: no Rio Grande do Sul, em Minas Gerais, no estado da Guanabara, incluindo a cidade do Rio de Janeiro, na Bahia e até mesmo em São Paulo. Em janeiro de 1970, a diretoria da SBF organiza na Cidade Universitária da USP o primeiro "Simpósio Nacional de Ensino de Física", de caráter amplo, abrangendo todos os níveis de ensino (com o apoio de diversas organizações, mas sem o apoio da Capes ou do $\mathrm{CNPq}$ ). Esta foi a primeira reunião de trabalho regular da SBF, fora do esquema proporcionado pela Reunião Anual da SBPC. Na época, a maior reunião de físicos era o Simpósio de Física Teórica, independente da SBF, que estava sendo realizado pela terceira vez, no Rio, em abril de 70 .

Entre outras preciosidades da ditadura, no final de 68 tinha sido publicado "ato complementar" vedando aos professores aposentados com base no "ato institucional número 5" a permanência e o acesso a instituições sustentadas por verbas públicas. Em 69, o
Almirante Octacilio Cunha, presidente do CBPF, assumindo o clima da época, decide aplicar a legislação, dispensando alguns pesquisadores, como Leite Lopes e Tiomno. O protesto da SBF foi imediato: a diretoria entregou uma petição ao Ministro-Chefe da Casa Civil da Presidência da República, apelando para o "direito ao trabalho", consagrado na "Declaração Universal dos Direitos do Homem"! Tratava-se realmente de uma época difícil.

\section{A SBF na ditadura - pri- meira metade da década de setenta}

Durante os anos mais difíceis da ditadura, embora permanecendo no exterior, Leite Lopes foi mantido na presidência da sociedade. A partir de 70, a vicepresidência foi assumida por Alceu G. Pinho-Filho, da PUC-RJ. Ainda sob o constrangimento das aposentadorias, a SBF se manifestou em São Paulo contra as prisões de Ernst W. e Amelia Imperio Hamburger. Nesta ocasião, Alceu Pinho e Ramayana Gazzinelli enviaram carta ao Presidente do CNPq pedindo que "não se tome como ameaça à segurança nacional qualquer atitude de crítica ou de não concordância", e observando que "freqüentemente, nem ao menos um processo normal de culpa é instaurado, sendo comum medidas repressivas serem tomadas sem proporção com os fatos que as motivaram...".

Em 71 a diretoria permanece praticamente inalterada, com Alceu Pinho na vice-presidência e Marcio Quintão Moreno, da UFMG, substituindo Ramayana Gazzinelli na secretaria de ensino. Surgem as primeiras discussões sobre a simplificação do currículo dos cursos de licenciatura. Decide-se realizar uma radiografia da "nova física" (isto é, da área de sólidos) no Brasil, promovendo cursos e mesas-redondas durante a Reunião Anual da SBPC. Realiza-se um dos primeiros levantamentos da pós-graduação em física no Brasil. Propõese a criação da Revista Brasileira de Física (RBF), escolhendo-se Jorge Leal Ferreira (IFT) como editorgeral, e Carlos A. Dias (UFBA), Alceu G. Pinho Filho (PUC-RJ), José Goldemberg (IFUSP), Ramayana Gazzinelli (UFMG), Sergio M. Rezende (UFPE), Marco A. Moreira (UFRGS) e Abraham H. Zimerman (IFT), como editores regionais.

Jorge Leal Ferreira foi editor da RBF de 71 a 78, sendo sucedido por Henrique Fleming (1978-1983) e posteriormente por Erasmo Madureira Ferreira, quando a revista passou a fazer parte do "primeiro patamar de revistas científicas brasileiras", com financiamento regular da Finep, através do recém criado "programa setorial de publicações em ciência e tecnologia". A Revista de Ensino de Física, editada por João Zanetic, foi lançada no Simpósio de Ensino de Física de 79. A Re- 
vista de Física Aplicada e Instrumentação surgiu bem mais tarde, em 1985, editada por Fernando C. Zawislak.

Em 73-74 a SBF realiza o primeiro estudo sobre a regulamentação da profissão de físico. Mais tarde, em 75, foi feito um levantamento dos físicos trabalhando na indústria, sendo enviada uma carta ao Ministério do Trabalho pedindo providências preliminares para a regulamentação da profissão. A iniciativa, no entanto, nunca encontrou terreno para prosperar. Também em 73-74, a diretoria patrocinou o primeiro levantamento de dados sobre a situação da física no Brasil, antecedendo trabalhos mais completos que foram posteriormente realizados pelo $\mathrm{CNPq}$.

\section{A SBF na ditadura - década de setenta, segunda metade}

Em julho de 75, durante a Reunião Anual da SBPC em Belo Horizonte, surgiram as primeiras notícias de que o governo Geisel tinha assinado um acordo comercial com a Alemanha a fim de construir algumas usinas nucleares em Angra dos Reis. Foi uma grande surpresa. Imediatamente se organizaram reuniões fora do programa oficial e o acordo com a Alemanha virou o grande tema do encontro. Na assembléia geral da SBF, embora as reservas em relação ao acordo fossem generalizadas, as opiniões eram divididas. A diretoria, sob a presidência de José Goldemberg, agia com cautela. Muitos físicos sempre criticaram a compra de pacotes tecnológicos, do tipo "caixa preta", como a usina instalada pela Westinghouse em Angra do Reis. Os reatores baseados em urânio natural, no estilo dos programas nucleares do Canadá ou da Índia, eram apontados como exemplo de caminho independente, evitando as dificuldades tecnológicas do enriquecimento pela ultracentrifugação. No acordo com a Alemanha também se falava em enriquecimento de urânio, mas através de uma nova tecnologia que seria integralmente transferida ao país. Por outro lado, o acordo era um grande mistério, aparentemente envolvendo investimentos da ordem de dez bilhões de dólares, com base em tecnologia que não havia sido posta à prova, numa situação em que o país ainda dispunha de grandes reservas energéticas.

Devido à sua atualidade, vale a pena transcrever os pontos da moção sobre o acordo nuclear, aprovada de forma praticamente unânime pela assembléia geral da $\mathrm{SBF}$, e posteriormente ratificada pela assembléia da SBPC:

(1) para que o desenvolvimento científico e tecnológico se realize, é indispensável a participação dos cientistas e técnicos brasileiros na formulação de métodos e sistemas utilizados e no debate político global sobre as opções energéticas do país;

(2) para que se consiga a formação de pessoal especializado em qualidade e quantidade compatíveis com uma política nuclear nacional, é imperiosa a participação das universidades brasileiras bem como a integração dos institutos de pesquisa nucleares ao setor universitário;

(3) é necessário que se analise o problema energético de maneira global e que o desenvolvimento dos reatores de potência se verifique paralelamente $\grave{a}$ pesquisa de outras formas de energia; em particular, exprimimos reservas quanto ao fato de que num país onde existem mais de cem mil megawatts hidráulicos seja necessário recorrer de imediato a uma solução nuclear dessa magnitude;

(4) a SBF reitera a sua posição contrária à utilização da energia nuclear para fins militares;

(5) o controle da ação sobre o meio ambiente (poluição radioativa e térmica), ao longo e após a execução do projeto, deve ser executado por uma organização idônea, como a SBPC, a exemplo do que é feito em paises com programas nucleares desenvolvidos;

(6) a SBF manifesta a sua opinião de que deve ser mantida a política de estrito monopólio estatal sobre os recursos naturais de importância energética;

(7) como condição para que qualquer destes pontos possa ser convenientemente considerado, e para que os cientistas e técnicos brasileiros participem deste debate, é indispensável que se discuta livre e abertamente os termos do acordo nuclear e suas implicações nos vários aspectos tecnológicos, econômicos, ecológicos e sociais da vida brasileira.

No Boletim publicado em setembro de 75 , o presidente da SBF, José Goldemberg, cita Einstein para explicar a posição dos físicos face ao acordo nuclear com a Alemanha: "os cientistas não podem, como tal, intervir diretamente, com sucesso, nas lutas políticas. Eles podem, contudo, promover a difusão de idéias claras e de possibilidades de ação que tenham sucesso. Eles podem contribuir através de esclarecimentos para impedir que os estadistas sejam prejudicados no seu trabalho por idéias antiquadas ou preconceitos." A SBF criou uma Comissão Especial, constituída por J. Goldemberg, F. C. Zawislak, L. Pingueli Rosa, J. I. Vargas e S. Watanabe, com observadores do MEC, do CNPq e da Nuclebrás S/A, que elabora um relatório detalhado sobre a "participação dos físicos no programa nuclear brasileiro". Durante mais de uma década, à medida que os sucessos, e principalmente os insucessos, do acordo com a Alemanha vão se desenrolando, os físicos participam ativamente do debate sobre a questão energética no Brasil (num período de dez anos, entre 78 e 88, há cerca de cinqüenta matérias publicadas no Boletim da SBF sobre diferentes aspectos da questão energética no país e do acordo nuclear). 


\section{Desdobramentos da questão nuclear - década de oitenta}

Na reunião da SBPC de 81, em pleno período de abertura controlada, o debate sobre a questão nuclear tomou novos rumos, ao sabor das denúncias de envio de urânio brasileiro ao Iraque e da existência de um "programa nuclear paralelo", com finalidades militares. A SBF decidiu indicar uma comissão para fazer um levantamento dos programas científicos com finalidades militares e das verbas que estariam sendo destinadas a estes programas, em detrimento de um apoio maior às atividades de ciência básica e aplicada. Um relatório assinado por Sergio Rezende, Solange de Barros e José Antonio de Freitas Pacheco acaba concluindo que não há evidências de que armas atômicas estejam sendo construídas ou projetadas em centros vinculados aos militares (que utilizam recursos da ordem de $10 \%$ do Fundo Nacional de Desenvolvimento Científico e Tecnológico, FNDCT, em programas de alta tecnologia).

No início de 82 o reator nuclear Angra I entra em funcionamento. A SBF expressa preocupações com questões de segurança, apontando que a energia elétrica adicional produzida não seria realmente necessária. Além disso, a CNEN, órgão fiscalizador de Angra, não tem qualquer independência em relação ao governo. Em 83, a SBF protesta contra decisão do governo colocando todas as atividades de pesquisa na área nuclear sob o controle da CNEN.

No final do período militar, pela primeira vez há uma nota conjunta de físicos brasileiros e argentinos. Nestes tempos de Mercosul, o documento pioneiro assinado por Fernando de Souza Barros, pela SBF, e Luiz Masperi, pela AFA, em novembro de 84, deveria ser lembrado com muito orgulho. As duas sociedades colocavam-se contrariamente à produção de armas nucleares em qualquer país, comprometiam-se a lutar pelo desarmamento nuclear geral, contra a corrida armamentista nos dois países, a favor de mecanismos de abertura e controle de todas as instalações nucleares. Além disso, concordavam que seria moralmente inaceitável a participação de físicos no desenvolvimento de armas nucleares de qualquer espécie.

Mais tarde, em 86, relatório da comissão de acompanhamento do programa nuclear, elaborado por Fernando de Souza Barros, Anselmo Paschoa e Luiz Pingueli Rosa, torna a concluir que, "no nível das informações disponíveis, o Brasil não dispõe de tecnologia completa para produzir a matéria prima para as bombas nucleares, isto é, as tecnologias de enriquecimento e re-processamento de urânio, embora haja um esforço para dominá-las com o objetivo de possuir o ciclo completo do combustível nuclear." A comissão também constata que o acordo com a Alemanha já estava praticamente congelado, com a construção da usina de reprocessamento suspensa e o enriquecimento por jato centrífugo ainda não comprovado comercialmente. O plutônio produzido em Angra não é disponível para uso diretamente, pois há controle da AIEA sobre os dejetos. Torna-se claro que o programa nuclear paralelo, de caráter secreto, executado no CTA, pela Aeronáutica, e no IPEN, pela Marinha, destina-se a desenvolver o ciclo completo e construir um submarino nuclear. No final de 86, a SBF e a AFA recebem com otimismo a declaração histórica do Presidente Sarney em Buenos Aires, garantindo que o Brasil não vai fabricar a bomba.

\section{Linhas de atuação da SBF - década de setenta}

Na Reunião Anual da SBPC em Recife, em 1974, o ministro Reis Velloso anuncia a criação do novo "Conselho Nacional de Desenvolvimento Científico e Tecnológico", que mantém a sigla CNPq. O novo CNPq absorve o Centro Brasileiro de Pesquisas Físicas, CBPF, como um instituto de pesquisa, em substituição à antiga sociedade civil, em situação de crise durante longo período. Criam-se os primeiros comitês assessores e se iniciam as discussões sobre os "indicadores de qualidade". Há muitas divergências com a burocracia do $\mathrm{CNPq}$, que acabam retratadas em vários números do Boletim da SBF. O Comitê Assessor de Física e Astronomia também inicia a prática de relatar as suas decisões (e principalmente dificuldades) através do Boletim da SBF. As primeiras instruções sobre as "regras do jogo" para as famosas "bolsas de pesquisa", que tanto têm contribuído para a sobrevivência dos cientistas no país, foram explicitadas no segundo Boletim de 1977 (e atualizadas posteriormente através de publicações em diversos números do Boletim até o início da década de 90).

A SBF foi designada pelo CNPq para representar o Brasil na União Internacional de Física Pura e Aplicada (IUPAP). Em setembro de 75, Erasmo M. Ferreira e Eugenio Lerner participam da assembléia geral da IUPAP, dando início ao nosso relacionamento com este organismo internacional.

Durante a Reunião Anual da SBPC em 1977, a SBF organizou um "Simpósio sobre Pesquisa em Física no Brasil", com trabalhos de Sergio M. Rezende e Gehrard Jacob.

Em 78 tem início a luta pela reintegração dos cientistas aposentados pelo AI-5. A SBF publica documento pedindo a reintegração de Mario Schemberg, José Leite Lopes, Jayme Tiomno, Sarah Castro Barbosa, Elisa Frota Pessoa e Plinio Susekind da Rocha (post mortem). Esta também é a época das "cassações brancas". A SBF reiteradamente denuncia a não concessão de licença para afastamento do país de professores das escolas públicas, as dificuldades à participação em congressos científicos no exterior, a exigência de atestados de ideologia, os vetos à contratação com base nestes atestados, a negação de bolsas de estudos, 
a exigência de antecedentes políticos aos pesquisadores estrangeiros no país, o não reconhecimento de diplomas obtidos nos países do leste europeu, a negativa de autorização para o comparecimento a reuniões da SBPC. Há um documento desta época, divulgado pela Secretaria Regional de São Paulo, que acabou sendo reproduzido no famoso "Livro Negro da USP". Em abril de 78, o Boletim da SBF publica notícia da nomeação de José Leite Lopes como professor universitário na França conservadora de Giscard d'Estaing.

O I Encontro Nacional de Física da Matéria Condensada (ENFMC) realizou-se em Cambuquira, MG, de 25 a 27 de maio de 1978, com a participação de cerca de 130 físicos. Os físicos presentes de nacionalidade brasileira assinaram uma carta ao presidente do CNPq protestando contra as cassações brancas. Foi feito um levantamento sobre a situação dos grupos de física da matéria condensada no Brasil. Os organizadores do encontro sabiam muito bem que o patrocínio da SBF seria essencial para garantir a continuidade da iniciativa. Por outro lado, também sabiam que esses encontros, de repercussão óbvia na física brasileira, acabariam consolidando a própria SBF. Os desenvolvimentos subseqüentes são bastante conhecidos.

A primeira Reunião de Trabalho sobre Física Nuclear no Brasil também se realizou em Cambuquira, de 3 a 9 de setembro de 1978, com a participação de mais de 50 físicos nucleares brasileiros (quase a totalidade), cinco físicos argentinos e um físico chileno. $\mathrm{Na}$ assembléia final do encontro votou-se resolução com críticas ao acordo nuclear, que não prevê o estabelecimento de uma tecnologia própria, à penúria de verbas em que se encontra a física nuclear brasileira (que não tem possibilidade de levar adiante projetos concebidos dez ou quinze anos atrás), às cassações brancas e à falta de regulamentação da profissão. O primeiro
Encontro Nacional de Física de Partículas Elementares e Campos foi realizado em Cambuquira, entre 6 e 9 de junho de 1979. Ao lado da reunião anual conjunta com a SBPC e do tradicional simpósio bianual de ensino, as três reuniões tópicas passaram a fazer parte do calendário anual de reuniões da SBF. Pouco mais tarde, foram adicionadas ao calendário as "escolas de verão", cujo nome representaria uma homenagem ao nosso colega ilustre, Jorge André Swieca (a primeira "escola de partículas e campos" realizou-se em São Paulo, em fevereiro de 81). Como secretário geral, Eugênio Lerner fez contatos com a Finep, viabilizando um apoio contínuo às reuniões e revistas da $\mathrm{SBF}$.

Na década de 80, a SBF manifesta-se muitas vezes sobre as políticas do CNPq e da Finep. Há também manifestações sobre questões específicas: crise na Unicamp, situação do CLAF, proposta para uma carreira de técnicos. A eleição de Tancredo Neves proporciona a elaboração de um documento que sintetiza as lutas e o pensamento da sociedade. Como ilustração, vale a pena relacionar os tópicos tratados nesse documento: (1) participação no processo decisório (estatutos do CNPq, estatutos da Finep), (2) verbas do FNDCT, (3) situação do PADCT, (4) incentivos à pesquisa na carreira universitária, (5) carreira para o pessoal técnico de apoio à pesquisa, (6) bolsas de pós-graduação, (7) infraestrutura para a pesquisa, (8) a questão do ensino básico, (9) o desenvolvimento de tecnologias que ameaçam o ambiente e a própria vida. Logo depois a SBF recebe muito positivamente as recomendações da "Comissão Nacional de Reformulação da Educação Superior": autonomia das instituições, reforma do Conselho Federal de Educação, fortalecimento da pesquisa e da pós-graduação, ênfase na qualidade, avaliação de desempenho com base em critérios bem estabelecidos. 